\title{
Role of Preoperative and Postoperative Colour Doppler Ultrasonography in Evaluation of AVF Creation and its Maturity in Patients Presenting to IGIMS, Patna
}

\author{
Chandra Bhushan Singh¹, Samiullah Hasan², Aishwarya Singh³, Sanjay Kr. Suman², Pankaj Kr. Gupta ${ }^{5}$
}

\author{
${ }^{1}$ Senior Resident, Department of Radiodiagnosis, IGIMS, Patna, Bihar, India. ${ }^{2}$ Senior Resident, Department of \\ Radiodiagnosis, IGIMS, Patna, Bihar, India. ${ }^{3}$ Senior Resident, Department of Radiodiagnosis, IGIMS, Patna, Bihar, India. \\ ${ }^{4}$ Professor and HOD, Department of Radiodiagnosis, IGIMS, Patna, Bihar, India. ${ }^{5}$ Senior Resident, Department of \\ Radiodiagnosis, IGIMS, Patna, Bihar, India.
}

\section{ABSTRACT}

\section{BACKGROUND}

In patients who require haemodialysis, native AV fistula is the vascular access of choice compared to central venous catheter and graft, as AVF lasts longer, and is associated with less number of complications. Currently frequent use of colour Doppler USG has resulted in increased number of patients who are eligible for AVF by identification of vessels. As duplex USG has a definite role in the early detection of complications, it results in increased native AVF longevity and survival. Duplex USG have many roles before and after AVF creation including preoperative vascular mapping, AVF maturation and surveillance. We wanted to evaluate the role of preoperative colour Doppler ultrasonography assessment of upper extremity vessels (artery \& vein) for haemodialysis access (AVF creation) \& its maturity.

\section{METHODS}

Prospective duplex USG study of upper limb vessels was done in 54 patients before haemodialysis access placement and ideal site was selected on the basis of standard parameters. Difference between USG and operative findings were analysed. The patients are usually first referred from nephrology department to the surgery department for AVF evaluation by physical examination. Surgeon selects preferred extremity for preoperative vascular mapping study \& sends patient to department of radiodiagnosis. If suitable vessels are identified during examination in surgery department, there is no need to examine the other limb. If surgeons are unable to identify suitable vessel in preferred extremity, then contralateral extremity will need to be studied along with preferred extremity.

\section{RESULTS}

Of all the 54 patients in whom vascular mapping was done and vascular access was placed, $96 \%$ have native AVF placed. In 98\% of patients, selected sites had vascular parameters which matched the operative findings. In $2 \%$ of patients, there was difference between duplex USG findings and operative findings. There was a very high correlation between the diameters of vessels (artery \& vein) measured by USG and surgery.

\section{CONCLUSIONS}

Preoperative \& postoperative USG evaluation of upper limb vessels prior to AVF creation has definite role in the selection of ideal site particularly in difficult patients in whom, evaluation by physical examination is not conclusive. It also has a definite role in the negative surgical exploration rate after preoperative assessment of vessels by duplex USG. There is almost complete reduction in negative surgical exploration for AVF creation. Duplex USG has a definite role in the early detection of complications \& assessment of maturity of AVF.

\section{KEY WORD}

Duplex USG, AVF, HD, Vascular Mapping, AVF Maturation, Monitoring \& Surveillance
Corresponding Author:

Sanjay Kr. Suman,

New Sinha Market,

Vachaspatinagar, Kumhrar,

Patna-800006, Bihar, India.

E-mail: dr.chandrabhushan05@gmail.com

DOI: $10.14260 /$ jemds/2019/681

Financial or Other Competing Interests: None.

How to Cite This Article:

Singh CB, Hasan S, Singh A, et al. Role of preoperative and postoperative colour doppler ultrasonography in evaluation of AVF creation and its maturity in patients presenting to IGIMS, Patna. Evolution Med. Dent. Sci. 2019;8(42):3140-3145, DOI: 10.14260/jemds/2019/681

Submission 10-07-2019,

Peer Review 01-10-2019,

Acceptance 08-10-2019,

Published 21-10-2019. 


\section{BACKGROUND}

Haemodialysis (HD) revolutionized the management of patients with renal failure. The rising prevalence of ESRD and consequent impact on health care economics has resulted in increasing focus on vascular access care. Vascular access in patients with ESRD is actually a lifeline providing a route for haemodialysis therapy. AVF is the most preferred access for HD. With time, increasing number of patients are requiring HD access. Complications following the procedure have been increasing as a major cause of morbidity and increased cost to patients for HD. Site for vascular access in our body are limited. Therefore, improve in longevity of vascular access is strongly needed. Mostly AVF failures are due to improper selection of vessels used for surgery. Duplex colour USG has unique ability to evaluate both structural and functional aspect of peripheral vessels. Therefore, preoperative evaluation with Doppler is strongly recommended which facilitate selection of suitable vessels \& reduces AVF failure significantly. There is no risk of phlebitis or contrast reaction unlike conventional venography. It gives many more anatomical details than physical examination by clinicians. It is especially useful in patients in whom visualization of veins is limited by body habitus, diabetes, elderly age group, and history of prior access. It is relatively less expensive, portable and requires minimal space \& setup. After installation of the AVF for HD, the patient may benefit from a quantitative criterion based on Doppler USG to access maturity. It increases success rate of AVF placement and maturation.

We wanted to evaluate the role of preoperative Doppler USG in planning vascular access placement with the subsequent decrease in negative surgical exploration, and the postoperative maturity.

\section{METHODS}

This prospective study of 54 patients was done in the the department of radiodiagnosis, IGIMS Patna between December 2018 to June 2019. The patient is usually first referred from nephrologist to the surgeon for physical assessment of upper limb for AVF creation. The vascular surgeon sends patient to radiodiagnosis department for assessment of the preferred upper limb. In 54 patients, evaluation of vessels of upper limb by surgeon were nonconclusive.

\section{Inclusion criteria}

All patients of renal failure who needed AVF creation for HD access referred from CTVS department to the department of radiodiagnosis.

\section{Exclusion criteria}

Patients with, upper limb arterial diseases like Raynaud's, patients with heart valves \& prosthesis, patients who had undergone arm, chest, neck surgery and patients who had undergone surgery for trauma, were excluded from the study.

\section{USG Evaluation of Upper Extremity Vessels}

This study was done on Samsung H60 ultrasound machine using $13 \mathrm{MHZ}$ linear probe. Almost all patient examination is performed in sitting position as most cases require bilateral upper limb examination. The limb under examination is properly exposed \& extended in a relaxed position on a support. Tourniquet is applied to the proximal part of the limb particularly during venous examination.

General Protocol [1 to 4]- Vessels under examination checked in both longitudinal and transverse plane. Transverse plane used to identify vessels (artery \& veins) \& evaluate diameter of vessels. Measurement taken at different levels caudal, mid \& cranial forearm near ACF \& at the caudal, mid \& cranial upper arm as needed.

Artery- Assessed for diameter, morphology of arterial wall for calcification \& luminal stenosis.

Vein- Assessed for compressibility to rule out occluding thrombus \& adequate drainage to deep venous system. Check for phlebitis, thrombus \& thrombophlebitis. Depth of CV from skin surface measured ( $>0.5 \mathrm{~cm}$ considered for transposition). For brachial artery anastomosis length of CV should extends 2 cms below \& BV $4 \mathrm{cms}$ above the ACF. Non dominant arm is preferred to create HD access. An AVF is placed first in the forearm if patient has suitable anatomy \& upper arm is saved for future potential dialysis access. Likewise, if an AVF cannot be placed, a forearm graft is preferred to placement of an upper arm graft. However, most will put an AVF in dominant arm before a graft is considered. Detail anatomy of branches is not necessary. Presence of large vein branches in the $10 \mathrm{~cm}$ of draining vein should be noted. Any variation at ACF is mandatory to identify. Two arteries at ACF indicate high bifurcation of the brachial artery. Predominant forearm CV and upper arm BV, double cephalic system, Y-shaped connection \& other variants. Colour and Spectral Doppler waveforms are obtained in longitudinal plane of vessels. Bilateral internal jugular and subclavian veins should be examined for symmetric respiratory phasicity and transmitted cardiac pulsatility. Unilateral or bilateral monophasic waveforms or low velocity venous waveforms are abnormal [1,2] need further evaluation. Marking of skin surface for mapping of the vascular system is done accordingly. An important aspect of planning for AVF and graft creation is vessel size and preferential order of placement as given in [Table-1,2].\{3,4,5\}

\section{Correlation with Surgery}

Results of USG were compared with per operative measurement of vessels used during surgery.

\begin{tabular}{|c|c|}
\hline Vessels & Minimum Diameter in $\mathbf{~ m m}$ \\
\hline Artery (AVF or graft) & 2 \\
\hline AVF vein & 2.5 (with tourniquet), 2.0 (without tourniquet) \\
\hline Graft vein & 4 \\
\hline Table 1. List of Minimum Diameter Criteria for AVF and Graft Creation \\
\hline
\end{tabular}

\begin{tabular}{|c|c|}
\hline $\begin{array}{c}\text { Order of Access } \\
\text { Placement }\end{array}$ & $\begin{array}{c}\text { Type of } \\
\text { Placement }\end{array}$ \\
\hline 1 & Non-dominant forearm AV fistula \\
\hline 2 & Dominant forearm AV fistula \\
\hline 3 & Non dominant or dominant upper arm cephalic vein fistula \\
\hline 4 & Non dominant or dominant upper arm basilic vein transposition fistula \\
\hline 5 & Forearm loopgraft \\
\hline 6 & Upper arm straight graft \\
\hline 7 & Upper arm loop graft (axillary artery to axillary vein) \\
\hline \multicolumn{2}{|c|}{ Table 2. List of Preferred Order of Vascular Access Placement } \\
\hline
\end{tabular}




\section{Statistical Analysis}

Analysis of data was done using data summarization in which calculation of appropriate statics and display of information was done in form of tables \& correlation statistics- graphs.

\begin{tabular}{|c|c|c|c|c|}
\hline \multicolumn{5}{|c|}{ RESULTS } \\
\hline \multirow{2}{*}{ Access } & \multirow{2}{*}{ Access Site } & \multicolumn{2}{|c|}{ Access Side } & \multirow{2}{*}{ Total } \\
\hline & & Right & Left & \\
\hline \multirow{5}{*}{ Fistula } & Radiocephalic & 4 & 12 & 16 \\
\hline & Brachiocephalic & 5 & 20 & 25 \\
\hline & Brachiobasilic & 3 & 6 & 9 \\
\hline & Brachiocubital & 1 & 1 & 2 \\
\hline & Total & 13 & 39 & 52 \\
\hline \multirow[t]{2}{*}{ Graft } & Arteriovenous & & 2 & 2 \\
\hline & Total & & & 54 \\
\hline \multicolumn{5}{|c|}{ Table 3. Type of Vascular Access } \\
\hline
\end{tabular}

\begin{tabular}{|c|c|c|c|c|c|c|}
\hline $\begin{array}{c}\text { Veins } \\
\text { (Ultrasound) }\end{array}$ & Axillary & Antecubital & Basilic & Cephalic & Thrombosed & \\
\hline Axillary & 2 & 0 & 0 & 0 & 0 & 2 \\
\hline Antecubital & 0 & 2 & 0 & 0 & 0 & 2 \\
\hline Basilic & 0 & 0 & 9 & 0 & 0 & 9 \\
\hline Cephalic & 0 & 0 & 0 & 39 & 2 & 41 \\
\hline Missed & 0 & 0 & 0 & 0 & 0 & 0 \\
\hline Total & $\mathbf{2}$ & $\mathbf{2}$ & $\mathbf{9}$ & $\mathbf{3 9}$ & $\mathbf{2}$ & $\mathbf{5 4}$ \\
\hline Table 4. Comparison of Veins Used between US and Surgery \\
\hline
\end{tabular}

\begin{tabular}{|c|c|c|c|}
\hline Arteries & $\mathbf{N}$ & $\begin{array}{c}\text { Mean Artery Size by } \\
\text { Ultrasound }\end{array}$ & $\begin{array}{c}\text { Surgically Measured } \\
\text { Mean Artery Size }\end{array}$ \\
\hline Radial & 16 & 2.21 & 2.42 \\
\hline Axillary & 1 & 4.42 & 4.53 \\
\hline Brachial fistula & 36 & 3.48 & 3.37 \\
\hline Brachial graft & 1 & 3.62 & 3.73 \\
\hline \multicolumn{3}{|c|}{ Table 5. US \& Surgical Measurements of Arteries } \\
\hline
\end{tabular}

\begin{tabular}{|c|c|c|c|}
\hline Veins & N & $\begin{array}{c}\text { Mean Vein Size by } \\
\text { Ultrasound }\end{array}$ & $\begin{array}{c}\text { Surgically Measured } \\
\text { Mean Vein Size }\end{array}$ \\
\hline Cephalic (wrist) & 16 & 2.12 & 2.01 \\
\hline Cephalic(elbow) & 25 & 2.86 & 2.72 \\
\hline Basilic & 9 & 2.45 & 2.31 \\
\hline Axillary & 2 & 5.12 & 4.72 \\
\hline Antecubital & 2 & 4.52 & 3.92 \\
\hline \multicolumn{3}{|c|}{ Table 6. US \& Surgical Measurements of Veins } \\
\hline
\end{tabular}

\begin{tabular}{|c|c|c|}
\hline Author & PE\% & (PE + DUSG)\% \\
\hline Allon et al.,[6] & 14 & 63 \\
\hline Silva et al., & 34 & 64 \\
\hline Wells et al., & $74(\mathrm{n}=145)$ & 86.5 \\
\hline Malvroh etal.,[7] & $0(\mathrm{n}=62)$ & 77 \\
\hline Present & 0 & 81 \\
\hline
\end{tabular}

Table 7. Comparison of the Present Study with other Studies for Increase in AVF Creation when Physical Examination was Combined with US for Preoperative Vascular Mapping

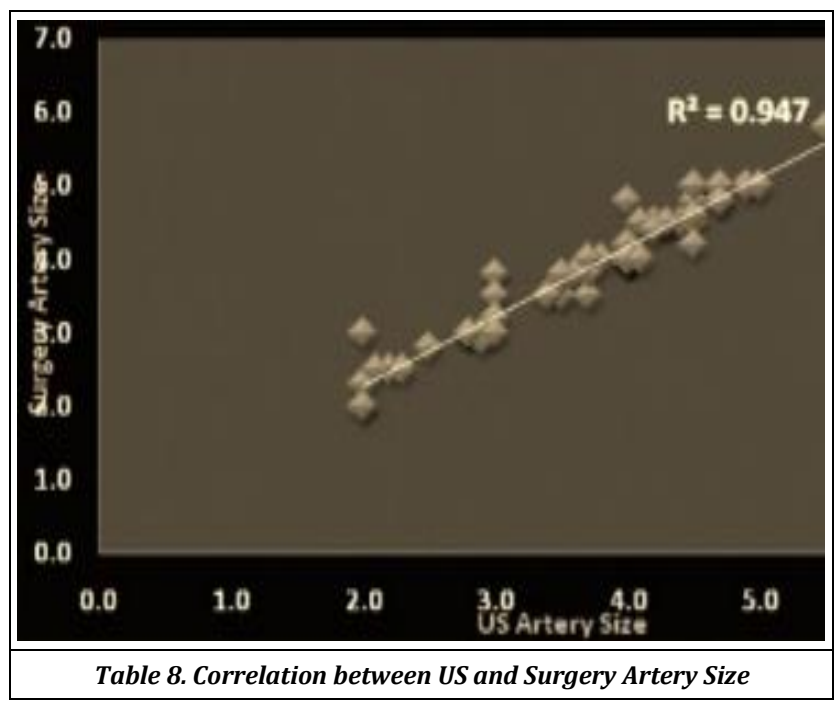

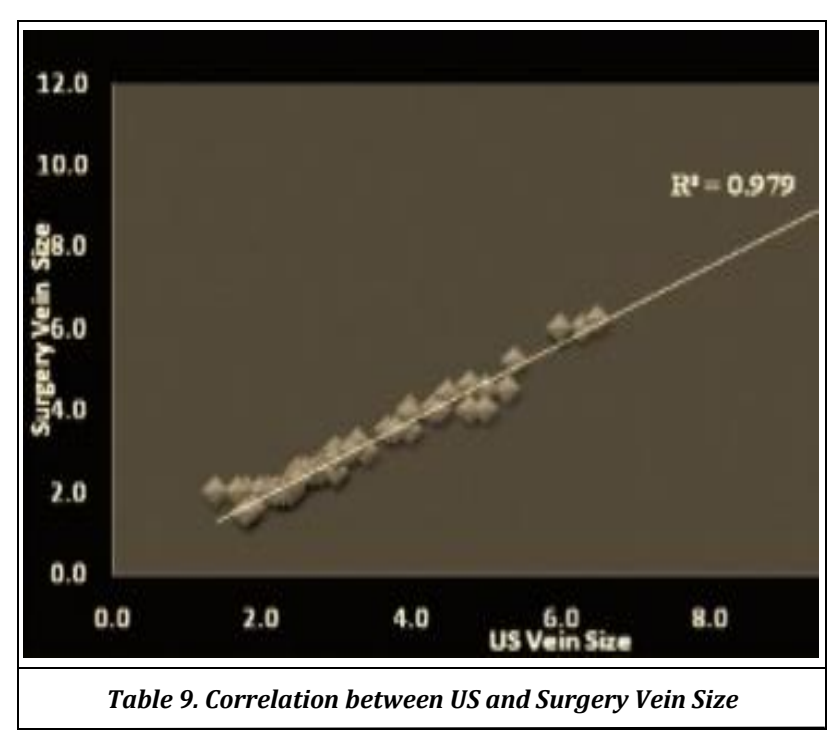

In our study, the highest number of cases was in the age group of 40 to 50 yrs. followed by the age group of 30 to 40 yrs. then between the age group of 50 to 70 yrs. Out of 54 patient 34 were males and 20 were females. Among 54 patients of CKD, most of them were diabetic \& hypertensive(70\%). $26 \%$ of patients had both DM \& HTN, $24 \%$ of patients were suffering from HTN alone and $20 \%$ of patients were suffering from DM alone, remaining patients were free from HTN \& DM. Out of 54 patients, 52 patients underwent native AVF and remaining two patients had graft (Table 3). In 75\% of patients left upper limb was selected for VA and in $25 \%$ patients, contralateral limb was selected for VA. In both sexes AVF as VA most commonly used. There was $100 \%$ correlation between the side of access selected \& type of access selected by USG and surgery. Also $100 \%$ correlation between the arteries selected by USG and utilized during surgery for VA. For veins $96 \%$ correlation found between veins selected by USG and vein used during surgery for VA (Table 4). Significant correlation was found between the diameter of arteries \& veins measured by the USG \& surgery (Table-8,9).

\section{AVF Maturation}

Adequate maturation renders an AVF suitable for venipuncture with large bore needles. In many cases, nonmaturation is the reason an AVF cannot be used for dialysis. $\mathrm{AV}$ anastomoses with native vessels has been associated with an incidence of early occlusion \& failure to mature (FTM) during the postoperative period. It is important to recall the proposal of Rayner et al. [8] which was incorporated in the KDOQI Guidelines[9] as "the Rule of 6". It identifies the ultrasound characteristics that confirm that a fistula is mature and therefore ready for use: a flow volume of $>600 \mathrm{ml} / \mathrm{min}$, an out-flow vein diameter of $\geq 6 \mathrm{~mm}$, and an out-flow vein depth of $\leq 6 \mathrm{~mm}$ below the skin surface (Fig. 6). If blood flow through the fistula is $250-500 \mathrm{ml} / \mathrm{min}$ on postoperative day 1 and 500 $900 \mathrm{ml} / \mathrm{min} 1$ month after construction of the anastomosis, maturation is likely (Fig. 5). Therefore, assessments of AVF maturation should always include a physical examination as well DUS measurements of the flow volume.

When performed correctly, calculation of the AVF flow volume by DUS is a simple procedure that can be completed in a few minutes and is highly reproducible. The vessel diameter and mean flow velocity (in $\mathrm{cm} / \mathrm{s}$ ) necessary for calculating 
flow volume $(\mathrm{ml} / \mathrm{min})$. In fact, once the two measurements have been made, further calculations are really not necessary: modern ultrasound scanners are equipped with computing algorithms for automatic calculation of the AVF flow volume. Measuring the flow volume at the level of the inflow artery improves accuracy and reproducibility.
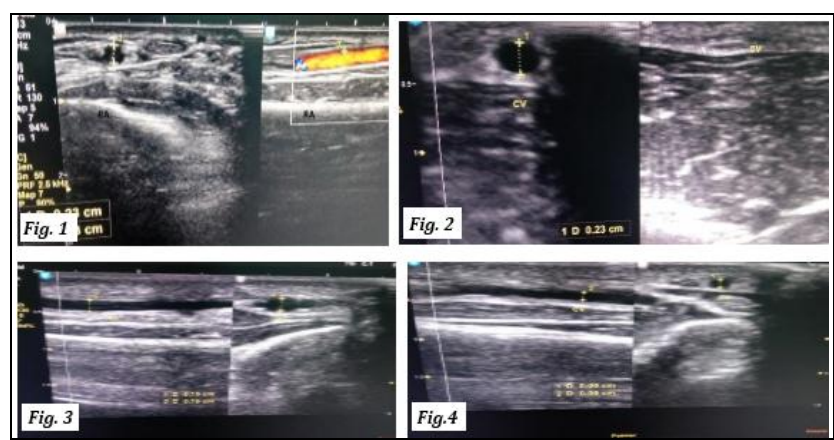

Figure 1. Demonstrating Adequate Diameter of Left Radial Artery at the Wrist ( $>2$ mm), Figure 2. Cephalic Vein at Wrist Demonstrating Adequate Diameter (>2 mm) and Patency by Compression of the Vein, Figure 3. Small Caliber Cephalic Vein (1.6 mm) Inadequate for AVF Creation, Figure 4. Small Caliber (0.9 mm) Radial Artery Inadequate for AVF Placement

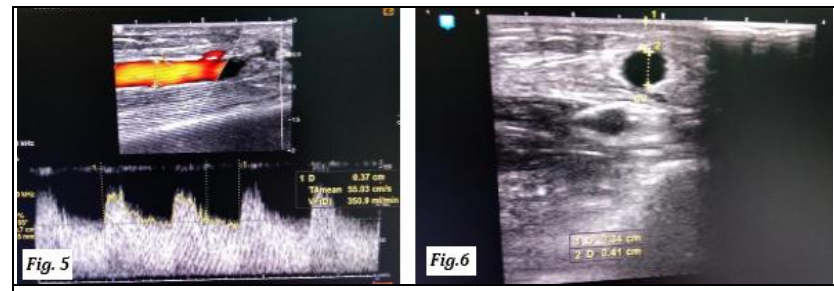

Figure 5. AVF Flow Volume Calculated at the Level of the Radial Artery after One Month of Fistula Formation at Wrist (AVF Fail to Mature as Flow Volume only Approx. $350 \mathrm{ml} / \mathrm{min}$ ), Figure 6. Distance of Anterior Wall of CV from Skin Surface (3.4 mm-Normal) \& Diameter (4.1 mm-Abnormal)

\section{DISCUSSION}

CKD is one of the major public health problems causes significant morbidity, mortality \& deterioration of quality of life. 100 to 220 per million is the incidence of stage 5 CKD in India, among them only $10 \%$ receive renal replacement therapy.

Haemodialysis (HD) is the most popular method of renal replacement therapy worldwide. HD is conducted by two methods, through a central venous dialysis catheter and other by permanent surgical access. Native AVF \& AV graft are two types of permanent surgically created HD access. A native AVF is a direct anastomosis between an artery and a vein, placed in either the forearm or upper arm. Connecting the artery to the vein causes increased blood flow into the vein. As a result, the vein grows larger and stronger, because of the greater flow of the arterialized blood through them, making repeated needle insertions for HD. ${ }^{[10,11]}$

Fistulas are preferred to graft because higher long-term patency rates, and lower rate of complications.[11,12] In our study out of 54 patients $96 \%$ were opted for native AVF \& remaining $4 \%$ for vascular grafts. Type of the VA depends on many factors like age, sex, race, presence of previous VA, other co-morbid conditions \& BMI. Allon M et al., in his study did not show any significant difference in the type of VA utilized on the basis of comorbid conditions like DM.
According to the various researches including Allon $\mathrm{M}$ et al., the native AVF as VA predominated in the male patients than in the female sex. In simple terms, vascular mapping is a way of evaluating arteries and veins for fistula creation. In general, three means are available to perform mapping: physical examination (PE), USG examination and angiographic evaluation.[12,13] $\mathrm{PE}$, a simple bedside assessment to evaluate the patency of the arterial and venous systems. PE can be valuable even used alone, but inadequate to identify suitable vasculature, particularly in obese patients or those with a history of prior VA therefore supplemented with USG.[14]

Duplex USG provide qualitative and quantitative data of vessels before AVF creation. Doppler USG can identify veins otherwise missed by PE. This approach is helpful in patients with DM and in the elderly due to arterial narrowing and calcification which are relatively common in patients with CKD. So arterial evaluation should be seriously carried out to know the patency, wall morphology, diameter and anatomical course while veins are seen for patency, diameter, length of a segment and depth.[13,14]

The internal diameter of the artery is measured in longitudinal or transverse sections. In the longitudinal section, the probe is aligned to show the intimal layers at the near and far walls to measure the distance from intima to intima perpendicular to the arterial wall. In the transverse section, the probe needs to be perpendicular to the skin surface and the long axis of the artery parallel to the skin surface to avoid diameter overestimation.[15] In the present study smallest mean arterial diameter measured by USG was $2.21 \mathrm{~mm}$ for radial artery \& largest mean arterial diameter is $4.42 \mathrm{~mm}$ for axillary artery. There was significant correlation between the diameters of arteries measured by USG \& by surgeons intra operatively [Table-5]. In a study by Malvroh et al. [16] mean radial artery diameter measured by USG and surgery was 2.3 +0.66 (range: $1.4-3.2$ ) and $2.1+0.58$ (range: 2.1-2.8) respectively. In this study, diameter of the radial artery measured by USG and surgery was $2.4 \pm 0.5$ (range: $2.0-3.8$ ) and $2.6 \pm 0.5$ (range: $2.0-4.0$ ) respectively.

Arterial wall calcifications, diffuse IMT \& atherosclerotic plaques play an important role in the longevity of VA, which are better picked by the B- mode USG. In the current study, the arteries with abnormal morphological changes were not selected for VA.

A peak systolic velocity (PSV) of at least $50 \mathrm{~cm} / \mathrm{sec}$ was found to be necessary for a successful fistula in a study by Sedlacek M et al.[17] In another study by Lockhart et al., arteries measuring $<2 \mathrm{~mm}$ in diameter were excluded, there was no difference in pre-operative PSV between adequate and inadequate fistulae \& no increased failure rate with a PSV of $<$ $50 \mathrm{~cm} / \mathrm{sec}$. Therefore, arterial diameter of $>2 \mathrm{~mm}$, arterial flow and PSV may be unimportant in determining fistula outcome. ${ }^{[18]}$ Since the mean smallest arterial diameter chosen for VA in our study was more than $2 \mathrm{~mm}$, we did not give importance to PSV.

The relationship between arterial diameters and AVF outcomes has been studied in radial-cephalic fistulas. Immediate (on the day of surgery) and early (within the first 8-12 weeks after surgery) AVF failures were found to be frequent when small-caliber $(<1.5-1.6 \mathrm{~mm})$ arteries were used to create the fistula. Malovrh et al. reported immediate and early failure rates of 55 and $64 \%$, respectively, when the 
arteries used had diameters of $\leq 1.5 \mathrm{~mm}$, whereas much lower rates ( 8 and $17 \%$, respectively) were observed when the arterial diameters were $>1.5 \mathrm{~mm} .{ }^{[19]}$ Parmar et al.[20] reported an early failure rate of $46 \%$ for arteries with diameters of $<1.5$ $\mathrm{mm}$, while no failures were observed when vessel diameters were $>1.5 \mathrm{~mm}$. Wong et al.[21] encountered premature failures with all AVFs created with arteries whose diameters were $\leq 1.6$ $\mathrm{mm}$. In another study, patent fistulae had preoperative radial diameters of $2.7 \mathrm{~mm}$ as opposed to $1.9 \mathrm{~mm}$ for AVFs that failed. Silva et al. proposed a minimal diameter of $2 \mathrm{~mm}$, which in their experience was associated with an early failure rate of 8 $\%$ and a 1-year primary patency rate of $83 \% .{ }^{[4]}$ However, AVF success rates of approximately $50 \%$ have been reported even when the arterial diameter is $<1.5 \mathrm{~mm}$. Therefore, ideal threshold for the diameter of the radial artery is inappropriate: the point to remember is that the likelihood of AVF patency and survival increases with the diameter of the artery used to create the fistula. [22,5]

There are no recommendations regarding the diameter of the brachial artery, which is constitutionally larger than that of the radial artery. Its assessment is less crucial to the success of the surgical procedure.[15] Calcifications are sonographically visualized as areas of hyper-echogenicity (with or without posterior shadowing) within the arterial wall and irregularities of the intima. In addition, they do not represent contraindications to AVF creation, but they can influence its outcome and/or surgery become more difficult.[23]

After the arterial assessment, venous assessment is important for successful VA. A normal vein has a thin and smooth wall, an anechoic lumen, and is fully compressible.[19] The vein mapped to receive arterial anastomosis should be measured after it is dilated. This size will more closely approximate the size of arterialized vein following fistula formation. The vein is generally dilated by use of tourniquet placement or an inflated blood pressure cuff on the arm. ${ }^{[24]}$

A minimum diameter of $2.5 \mathrm{~mm}$ with tourniquet was first suggested by Silva who reported good AVF outcomes (8\% early failure, $83 \%$ functional primary patency at $1 \mathrm{y}$ ), in the absence of a tourniquet, Mendes et al.[25] propose a diameter of $>2 \mathrm{~mm}$. Well-documented indications on the minimum diameter for the veins of the arm are also lacking.

Lockhart et al.[24,26] reported that cephalic veins with a pretourniquet diameter of $\geq 2.5 \mathrm{~mm}$ and smaller veins with a posttourniquet diameter $\geq 2.5 \mathrm{~mm}$ were equally useful for creating dialysis fistulas. Some authors have suggested that the likelihood of non-maturation is related to the presence and diameter of accessory veins. Wong et al.[21] found that the presence of accessory veins less than $5 \mathrm{~cm}$ from the site chosen for the anastomosis, while Beathard et al. stressed the importance of the dimensions of these veins and reported higher frequencies of non-maturation when the AVF was near large collateral veins. [27]

Minimum mean diameter of vein for VA measured by USG is $2.12 \mathrm{~mm}$ for CV \& maximum diameter of $5.12 \mathrm{~mm}$ for axillary veins. There is notable correlation found between the diameters of veins measured by USG \& by surgeons intraoperatively [Table-6].

Fistulas created with small-caliber veins $(<1.6 \mathrm{~mm})$ are at high risk for early failure, ${ }^{[21]}$ but there is no consensus on the minimum cephalic vein diameter that will ensure good maturation of AVF. In our study three anatomical variations were found which helped in planning for surgery. Two were high brachial artery bifurcation and another one was cephalic vein duplication. Preoperative vessels mapping with USG has led to remarkable increase in AVF placements when compared with PE alone, particularly in patients with inadequate PE due to obesity, or those with a history of previous vascular access. Various studies show that there is a consequential increase in the incidence of successful VA after USG vascular mapping than with physical mapping alone [Table-7].[28]

The prevailing study shows accuracy of $95 \%$ for selecting the type of VA in CRF patients. There is substantial decrease in negative surgical exploration rates with preoperative vascular USG. Malv Roh et al.[16] documented 0\% negative surgical exploration rate. Another study by Allon et al.,[29] showed $11 \%$ (28 of 256) negative surgical exploration rate.

In the present study there was $0 \%$ negative surgical exploration rate. $4 \%$ of the USG selected veins did not match the operative findings. However, this did not yield to negative surgical exploration as other suitable vessels were found nearby. These differences were seen in the veins of cubital region and were attributed to the confusing venous variations of the cubital region. Hence, knowledge of anatomical variations can reduce discrepancies and better surgical management (Fig. 1, 2, 3, 4).

\section{CONCLUSIONS}

Native AVF is the vascular access of choice for patients requiring HD. In HD, patient benefits translate to better quality of life \& longer survival. Vessel diameter, wall morphology \& variation in their anatomy are various parameters which can be evaluated by preoperative Doppler USG vascular mapping \& selecting ideal site for haemodialysis access. Duplex USG is fundamental for evaluation of access maturity \& early detection of complications. This facilitates timely targeted intervention that prolong the survival of the vascular access.

\section{REFERENCES}

[1] Chin EE, Zimmerman PT, Grant EG. Sonographic evaluation of upper extremity deep venous thrombosis. J Ultrasound Med 2005;24(6):829-38, quiz 839-40.

[2] Patel MC, Berman LH, Moss HA, et al. Subclavian and internal jugular veins at Doppler US: abnormal cardiac pulsatility and respiratory phasicity as a predictor of complete central occlusion. Radiology 1999;211(2):57983.

[3] Allon M, Robbin ML. Increasing arteriovenous fistulas in haemodialysis patients: problems and solutions. Kidney Int 2002;62(4):1109-24.

[4] Silva MB Jr, Hobson RW 2nd, Pappas PJ, et al. A strategy for increasing use of autogenous haemodialysis access procedures: impact of preoperative noninvasive evaluation. J Vasc Surg 1998;27(2):302-08. 
[5] Lemson MS, Leunissen KM, Tordoir JH. Does preoperative duplex examination improve patency rates of BresciaCimino fistulas? Nephrol Dial Transplant 1998;13(6):1360-1.

[6] Griffith C, Reus J, Robinson K, et al. Duplex of upper extremity vessels prior to AVF surgery. Olympic Vascular Surgical Associates 2011: p. 01-06.

[7] ACR-AIUM-SRU Practice guideline for the performance of ultrasound vascular mapping for preoperative planning of dialysis. Practice Guideline, Ultrasound mapping for preoperative planning - Revised 2011;(Resolution 9):0104.

[8] Rayner HC, Pisoni RL, Gillespie BW, et al. Creation, cannulation and survival of arteriovenous fistulae: data from the dialysis outcomes and practice patterns study. Kidney Int 2003;63(1):323-30.

[9] Vascular Access 2006 Work Group. Clinical practice guidelines for vascular access. Am J Kidney Dis 2006;48(Suppl 1):S176-S247.

[10] Modi GK, Jha V. The incidence of end-stage renal disease in India: a population-based study. Kidney Int 2006;70(12):2131-3.

[11] National Kidney Foundation. III. NKF-K/DOQI Clinical Practice Guidelines for Vascular Access: 2000. Am J Kidney Dis 2001;37(1 Suppl 1):S137-81.

[12] Vascular Access Work Group. Clinical practice guidelines for vascular access. Am J Kidney Dis 2006;48(Suppl 1): S248-73.

[13] Asif A, Ravani P, Roy-Chaudhury P, et al. Vascular mapping techniques: Advantages and disadvantages. J Nephrol 2007;20(3):299-303.

[14] Niyyar VD, Wasse H, et al. Vascular mapping: does it help to maximize fistulae placement? Adv Chronic Kidney Dis 2009;16(5):316-20.

[15] Ferring M, Henderson J, Wilmink A, et al. Vascular ultrasound for the pre-operative evaluation prior to arteriovenous fistula formation for haemodialysis: review of the evidence. Nephrol Dial Transplant 2008;23(6):1809-15.

[16] Malovrh M. Native arteriovenous fistula: preoperative evaluation. Am J Kidney Dis 2002;39(6):1218-25.

[17] Sedlacek M, Teodorescu V, Falk A, et al. haemodialysis access placement with preoperative noninvasive vascular mapping: comparison between patients with and without diabetes. Am J Kidney Dis 2001;38(3):560-4.
[18] Lockhart ME, Robbin ML, Allon M. Preoperative sonographic radial artery evaluation and correlation with subsequent radiocephalic fistula outcome. J Ultrasound Med 2004;23(2):161-8, quiz 169-71.

[19] Zwiebel WJ. Extremity venous anatomy, terminology, and ultrasound features of normal veins. In: Zwiebel W, Pellerito J, eds. Introduction to vascular ultrasonography. Philadelphia, PA: Elsevier Saunders 2005: p. 415-29.

[20] Parmar J, Aslam M, Standfield N. Pre-operative radial arterial diameter predicts early failure of arteriovenous fistula (AVF) for haemodialysis. Eur J Vasc Endovasc Surg 2007;33(1):113-5.

[21] Wong V, Ward R, Taylor J, et al. Factors associated with early failure of arteriovenous fistulae for haemodialysis access. Eur J Vasc Endovasc Surg 1996;12(2):207-13.

[22] Malovrh M. Non-invasive evaluation of vessels by duplex sonography prior to construction of arteriovenous fistulas for haemodialysis. Nephrol Dial Transpl 1998;13(1):125-9.

[23] Malovrh M. The role of sonography in the planning of arteriovenous fistulas for haemodialysis. Semin Dial 2003;16(4):299-303.

[24] Lockhart ME, Robbin ML, Fineberg NS, et al. Cephalic vein measurement before forearm fistula creation: does the use of a tourniquet to meet the venous diameter threshold increases the number of usable fistulas? J Ultrasound Med 2006;25(12):1541-5.

[25] Mendes RR, Farber MA, Marston WA, et al. Prediction of wrist arteriovenous fistula maturation with preoperative vein mapping with ultrasonography. J Vasc Surg 2002;36(3):460-3.

[26] Planken RN, Tordoir JH, Duijm LE, et al. Current techniques for assessment of upper extremity vasculature prior to haemodialysis vascular access creation. Eur Radiol 2007;17(11):3001-11.

[27] Beathard GA, Arnold P, Jackson J, et al. Aggressive treatment of early fistula failure. Kidney Int 2003;64(4):1487-94.

[28] Wells AC, Fernando B, Butler A, et al. Selective use of ultrasonographic vascular mapping in the assessment of patients before haemodialysis access surgery. Br J Surg 2005;92(11):1439-43.

[29] Allon M, Lockhart ME, Lilly RZ, et al. Effect of preoperative sonographic mapping on vascular access outcomes in haemodialysis patients. Kidney Int 2001;60(5):2013-20. 